Correction

\title{
Correction: Clinical impact of measurable residual disease monitoring by ultradeep next generation sequencing in NPM1 mutated acute myeloid leukemia
}

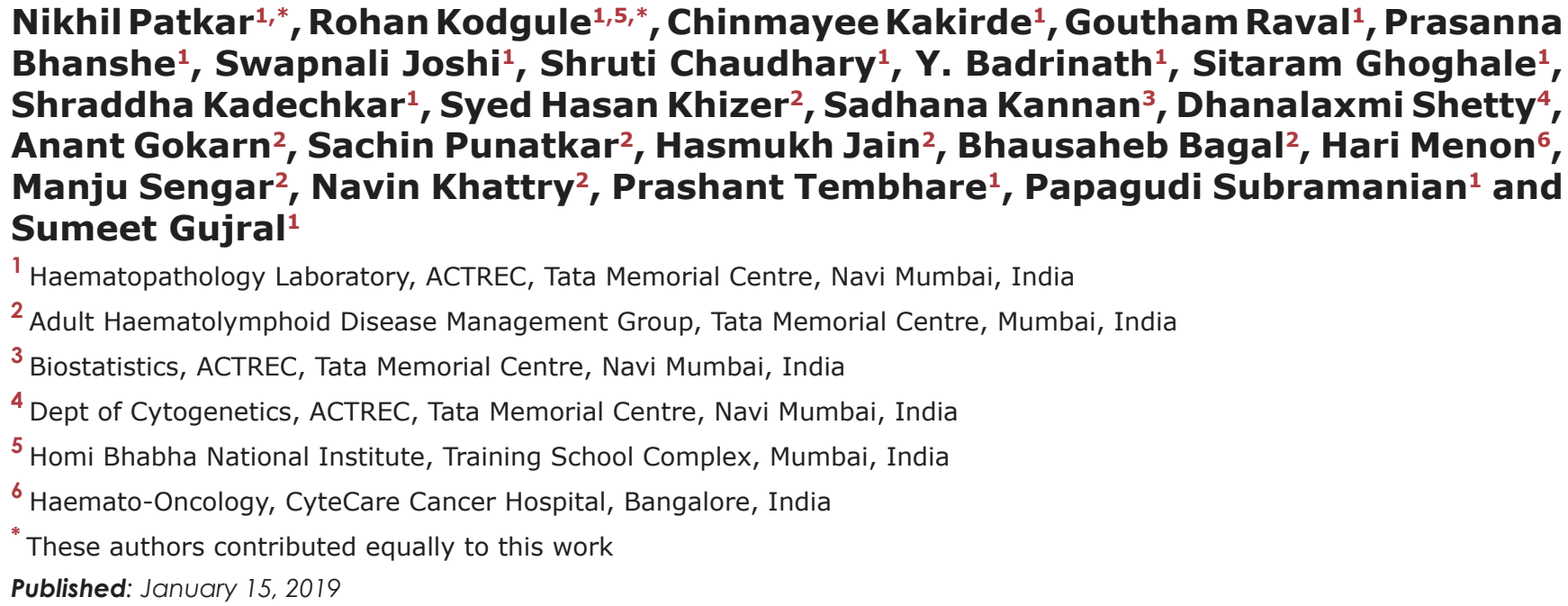
Bhanshe $^{1}$, Swapnali Joshi ${ }^{1}$, Shruti Chaudhary ${ }^{1}$, Y. Badrinath ${ }^{1}$, Sitaram Ghoghale ${ }^{1}$, Shraddha Kadechkar ${ }^{1}$, Syed Hasan Khizer ${ }^{2}$, Sadhana Kannan ${ }^{3}$, Dhanalaxmi Shetty ${ }^{4}$, Anant Gokarn², Sachin Punatkar ${ }^{2}$, Hasmukh Jain², Bhausaheb Bagal ${ }^{2}$, Hari Menon ${ }^{6}$, Manju Sengar ${ }^{2}$, Navin Khattry ${ }^{2}$, Prashant Tembhare ${ }^{1}$, Papagudi Subramanian ${ }^{1}$ and Sumeet Gujral ${ }^{1}$

${ }^{1}$ Haematopathology Laboratory, ACTREC, Tata Memorial Centre, Navi Mumbai, India

${ }^{2}$ Adult Haematolymphoid Disease Management Group, Tata Memorial Centre, Mumbai, India

3 Biostatistics, ACTREC, Tata Memorial Centre, Navi Mumbai, India

${ }^{4}$ Dept of Cytogenetics, ACTREC, Tata Memorial Centre, Navi Mumbai, India

${ }^{5}$ Homi Bhabha National Institute, Training School Complex, Mumbai, India

${ }^{6}$ Haemato-Oncology, CyteCare Cancer Hospital, Bangalore, India

${ }^{*}$ These authors contributed equally to this work

Published: January 15, 2019

Copyright: Patkar et al. This is an open-access article distributed under the terms of the Creative Commons Attribution License 3.0 (CC BY 3.0), which permits unrestricted use, distribution, and reproduction in any medium, provided the original author and source are credited.

This article has been corrected: The correct Funding information is given below:

\section{FUNDING}

This work was supported by the Wellcome Trust/DBT India Alliance Fellowship [grant number IA/CPHI/14/1/501485] awarded to Dr Nikhil Patkar. Initial part of the study (8 colour FCM) was funded by a Lady Tata Memorial Trust Grant awarded to Prof Navin Khattry.

Original article: Oncotarget. 2018; 9:36613-36624. https://doi.org/10.18632/oncotarget.26400 